\title{
A System Dynamics Approach to Eco-Industry System Effects and Trends
}

\author{
Huilu Yü ${ }^{1,2}$, Suocheng Dong ${ }^{1}$, Fei Li ${ }^{1 *}$ \\ ${ }^{1}$ Institute of Geographic Sciences and Natural Resources Research, Chinese Academy of Sciences, Beijing, China \\ ${ }^{2}$ College of Resources and Environmental Engineering, Ludong University, Yantai, China
}

Received: 7 September 2017

Accepted: 25 March 2018

\begin{abstract}
Ecological industry can be thought of as a move toward sustainable development while reducing waste and avoiding pollution, especially in resource-based cities. This study presents a system dynamics approach to analyzing the environmental and economic effects of the eco-industry system by simulating long-term trends. Focusing on West China's typical coal-based city of Huinong, a system dynamics model named industry-effect-policy system dynamics (IEP-SD) has been designed to evaluate the integrated effects of the industrial system. The simulation results indicate progressive environmental and economic benefits of the eco-industry system, along with prospective economic growth. In addition, the model identifies some defects and disadvantages of western China's typical industry system, such as the extensive increase of local policy-preferential industrial sectors, limited and torpid development of other industries, and a certain level of industrial structure instability. An industrial structure coordination option is finally offered and then proved by the model to balance local environmental and economic effects.
\end{abstract}

Keywords: eco-industry, system dynamics, coal resource-based city, China

\section{Introduction}

Ecological industry (eco-industry) can be defined as an environment-economy model wherein planning, resourcing, procurement, production, and reprocessing are designed and managed, as both process and output, to maximize ecosystem functioning and human wellbeing [1-3]. The sprouting of eco-industry thinking goes back to the 1960s. In 1966, an essay called The Economics of the Coming Spaceship Earth presented Earth as a closed system and argued that the outputs of

*e-mail: 1f@igsnrr.ac.cn all parts of the closed system are linked to the inputs of other parts [4], contributing to the development of eco-industry thought. The concepts of eco-industry and circular economy were introduced in 1990 [5], and one common feature of eco-industry was to prevent further environmental deterioration and to conserve natural resources through effective waste management, especially in resource-based cities. Many modes of ecoindustry have been well implemented in some developed countries, such as resource-based cities in some OECD countries, accompanied by the enactment of some regulations and laws $[1,6,7]$.

China's eco-industry has developed very rapidly since 2000, after the concept of industrial ecology 
Table 1. Abbreviations of industry terms.

\begin{tabular}{|c|c|}
\hline Industry terms & Abbreviation \\
\hline Industrial enterprises above designated size & IEADS \\
\hline $\begin{array}{c}\text { Coal-electric power-metallurgy-machinery } \\
\text { industry chain }\end{array}$ & CEMM \\
\hline $\begin{array}{c}\text { Limestone-lime nitrogen-cyanamide } \\
\text {-building material industry chain }\end{array}$ & LLCB \\
\hline Policy-preferential industrial sectors & PIS \\
\hline Policy-constricted industrial sectors & CIS \\
\hline Transformation towards a circular economy & TTCE \\
\hline Blast furnace gas & BFG \\
\hline Calcium carbide furnace gas & CCFG \\
\hline Coke furnace gas & CFG \\
\hline Submerged arc furnace gas & SAFG \\
\hline Decreasing backward production capacity & DBPC \\
\hline Industrial upgrading & IU \\
\hline Ferroalloy calcium carbide coke & FCCC \\
\hline Magnesium deep processing & MDP \\
\hline Chlor alkali deep processing & CADP \\
\hline Building material industry using wastes & BMIUW \\
\hline
\end{tabular}

was introduced around the end of the 1990s [8, 9]. Eco-industry is increasingly viewed as significance to China's industrial development into a more sustainable economy, given more severe shortages of natural resources and environmental degradation [1, 8]. In such a large and typical transitional economy, up-bottompolicy has played a vital role in implementing regional ecological industrial initiatives in China. This includes implementing various levels of local regulations to optimize industrial structure, industrial upgrading, and transformation toward a circular economy. However, a bottom-up approach based on industrial sectors and enterprises is insufficient for industrial transition, which is critical and also influenced by market factors and private sectors $[3,9]$. As a whole, industry is the main domain in which sustainability steps are implemented in China. China's eco-industry is now actively promoted at various levels of industrial parks, with many nation-level pilot demonstration projects being carried out. Therefore, some eco-industry parks play a very important role in joining micro-sector enterprises to macro-level regions [10, 11]. Eco-industry benefits can be promoted by transforming industrial structure and rearranging industrial layout, as well as by eliminating heavily polluting enterprises [10, 12]. In some recent literature, the operation mechanism $[3,13]$, comprehensive performance assessment [14, $15]$, and key driving factors [16, 17] of eco-industry have been analysed significantly. However, few studies have systematically related the regulation and operation of eco-industry to its effects and benefits, especially concerning underdeveloped resource-based cities of developing countries and the transformation of economies confronting severe environmental pollution, resource depletion, and socioeconomic risks. It is crucial to clarify the long-run effects imposed by eco-industry on the development of regional economies and environments. Thus, taking the case of the industrial system in Huinong of Ningxia, a typical coal-based city in western China, a system dynamics model of the eco-industry, named as industry-effectpolicy system dynamics (IEP-SD), is presented. The model's goal is to quantitatively simulate various flows in the eco-industry system, explore effects and long-run trends, and detect systematic defects. Options for transforming and improving industry are then discussed.

\section{Material and Methods}

Huinong $\left(106^{\circ} 42^{\prime}-106^{\circ} 48^{\prime} \mathrm{E}, 39^{\circ} 12^{\prime}-39^{\circ} 18^{\prime} \mathrm{N}\right)$ is a famous resource-based city in western China. With rich coal, Huinong is one of the most important industry bases in northwestern China. It is also one of the most seriously polluted areas of China, with a typical heavy coal-based industrial structure. Recently, there have been some efforts to ameliorate the resource city-related environment and economy, mainly focusing on the development of eco-industry in Huinong, especially since 2007. There are presently 17 main industrial products in 82 of Huinong's industrial enterprises above designated size (IEADS; all the abbreviation of the industry terms are in Table 1). More than $85 \%$ of these enterprises can be incorporated into the three main industrial chains, including the coal industry-electric power industrymetallurgical industry-machinery industry (CEMM) chain, the limestone-lime nitrogen industry-cyanamide industry-building materials industry (LLCB) chain, and the coal-chemical industrial chain. All these industrial chains are based on the comprehensive utilization of coal resources. So far, Huinong's local eco-industry and industrial sustainability measures mainly involve decreasing backward production capacity, industrial upgrading, and transformation toward a circular economy.

\section{System Dynamics}

System dynamics, first proposed in the 1950s [18], is herein applied to construct a systemic analysis model of eco-industry. This method has been used in many studies of economically and environmentally complex systems around the world, including China $[19,20]$, which is characterized by quantifiability and controllability, and could reveal the dynamic changes, feedback, delay, and other processes of a complex system [21]. Thus, this method could have an outstanding advantage in analysing, improving, and managing a 


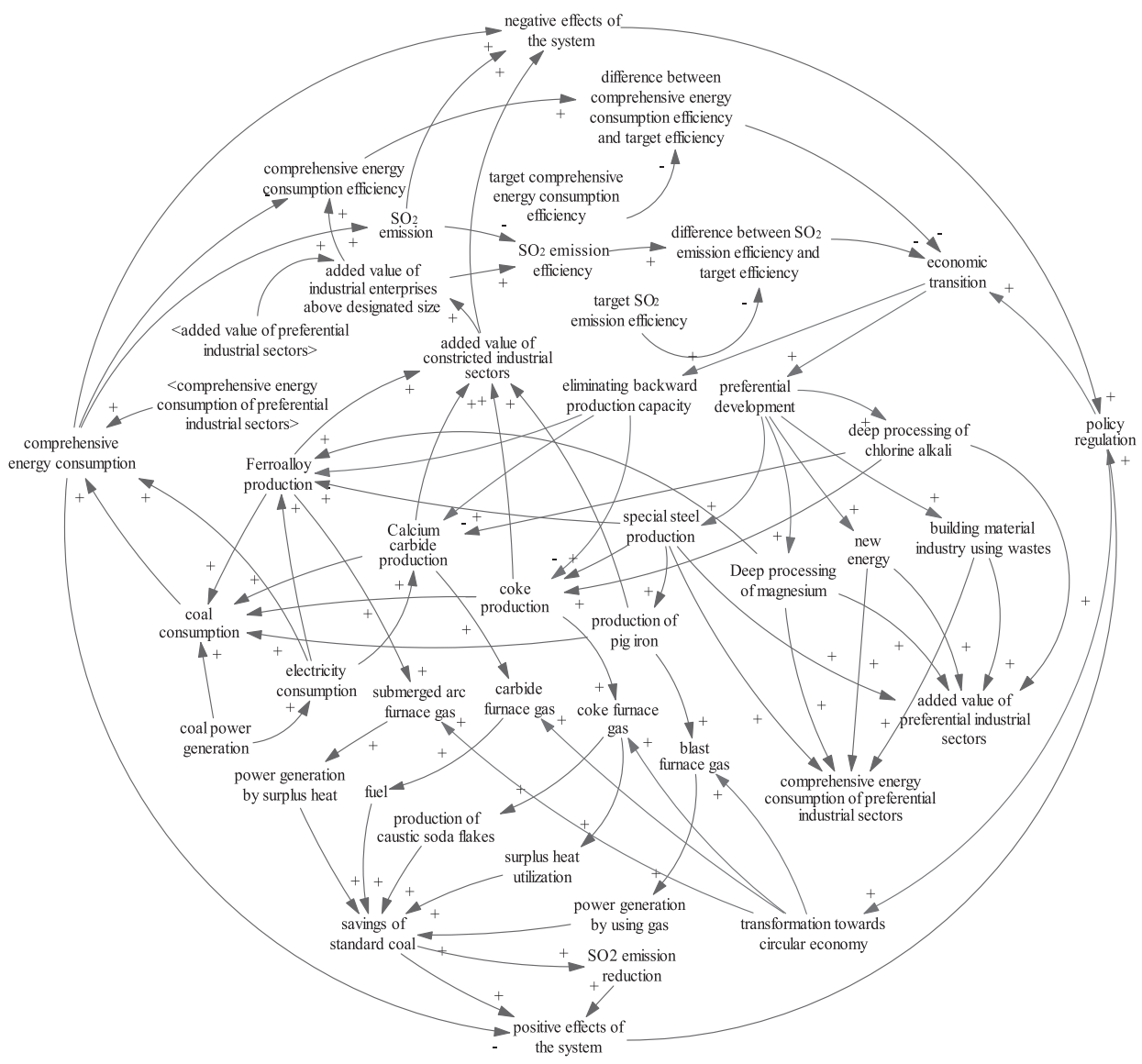

Fig. 1. Causal loop of the IEP-SD model.

system with a long development cycle and complex feedback effects [22, 23]. In this study, Huinong's entire eco-industry system is composed of three subsystems: industry, effect, and policy. The industry subsystem mainly involves the above three Huinong industrial chains. This industry subsystem might run with positive effects, such as economic growth, employment increase, and pollution reduction, and perhaps negative effects such as industrial structure imbalance. The industry subsystem could interact with the effect subsystem. The trends of these effects could be manifested gradually and might in turn counteract the industry subsystem. The imbalance of industrial structure might increase the cost of production and would impede the industrial growth in the long run. To implement a policy subsystem, some structure regulation and eco-industrypromoting policies could be carried out to increase positive effects while decreasing negative effects. The policy subsystem could coordinate with the effect subsystem and industry subsystem, eventually helping to improve the sustainability of the whole eco-industry system.

The data of this study are mainly from a survey of enterprises in Huinong and official public documents. In 2015 and 2016, more than 150 industrial firms were investigated with questionnaires. The governmental reports and materials are provided by the local Development and Reform Commission, the Bureau of
Statistics, and other administrative bureaus of Huinong, such as Huinong's annual statistical production report of industry and business, various Huinong statistical yearbooks, the annual circular economy development report from 2007 to 2015, and the special planning for eco-industry in Huinong.

\section{IEP-SD Modelling}

The causal loop diagram of the IEP-SD model (Fig. 1) is designed according to a material-energy flow analysis of the eco-industry system. In this diagram, the red arrows indicate paths of policy formulation and regulation, and the blue arrows indicate eco-industry's systemic positive and negative effects on the industrial chains. The stock-flow diagram of the IEP-SD model is constructed with the three subsystems connected to each other, based on the causal loop diagram of Huinong's eco-industry system. This is applied to analyse the interaction effects of different subsystems and feedback relationships within the parameters of the model, thereby providing a quantitative demonstration and simulation of the development process of the ecoindustry system. The stock-flow diagram is divided into three modules: the off-gas comprehensive utilization module, the policy-preferential industrial module (PIS), and the regulating effect module. Here, $\mathrm{SO}_{2}$ removal is related to $\mathrm{SO}_{2}$ emission reduction, and $\mathrm{SO}_{2}$ emission 


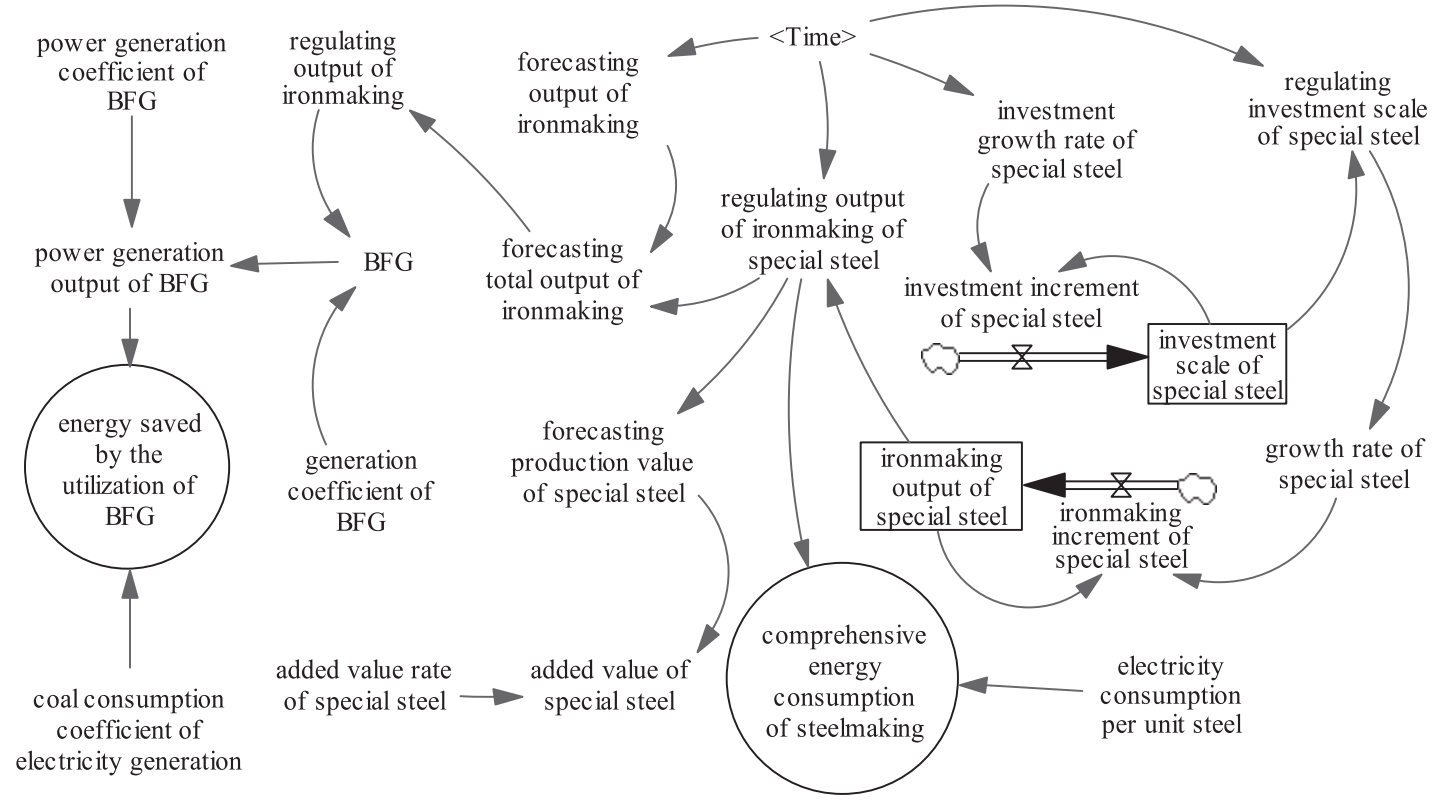

Fig. 2. Stock-flow diagram of BFG utilization.

efficiency involves the ratio of $\mathrm{SO}_{2}$ emissions to added value of the industrial sector.

\section{Off-Gas Comprehensive Utilization Module}

Transformation towards a circular economy (TTCE) in Huinong includes the comprehensive utilization of blast furnace gas (BFG), calcium carbide furnace gas (CCFG), coke furnace gas (CFG), and submerged arc furnace gas (SAFG). These sections of resource use are strongly relied on to promote an industrial ecology level, and nearly $50 \%$ of public subsidies are invested in these fields. The utilization processes and energy-saving effects of these four types of industries are simulated and estimated in this module, which includes four submodules: BFG utilization, CCFG utilization, CFG utilization, and SAFG utilization.

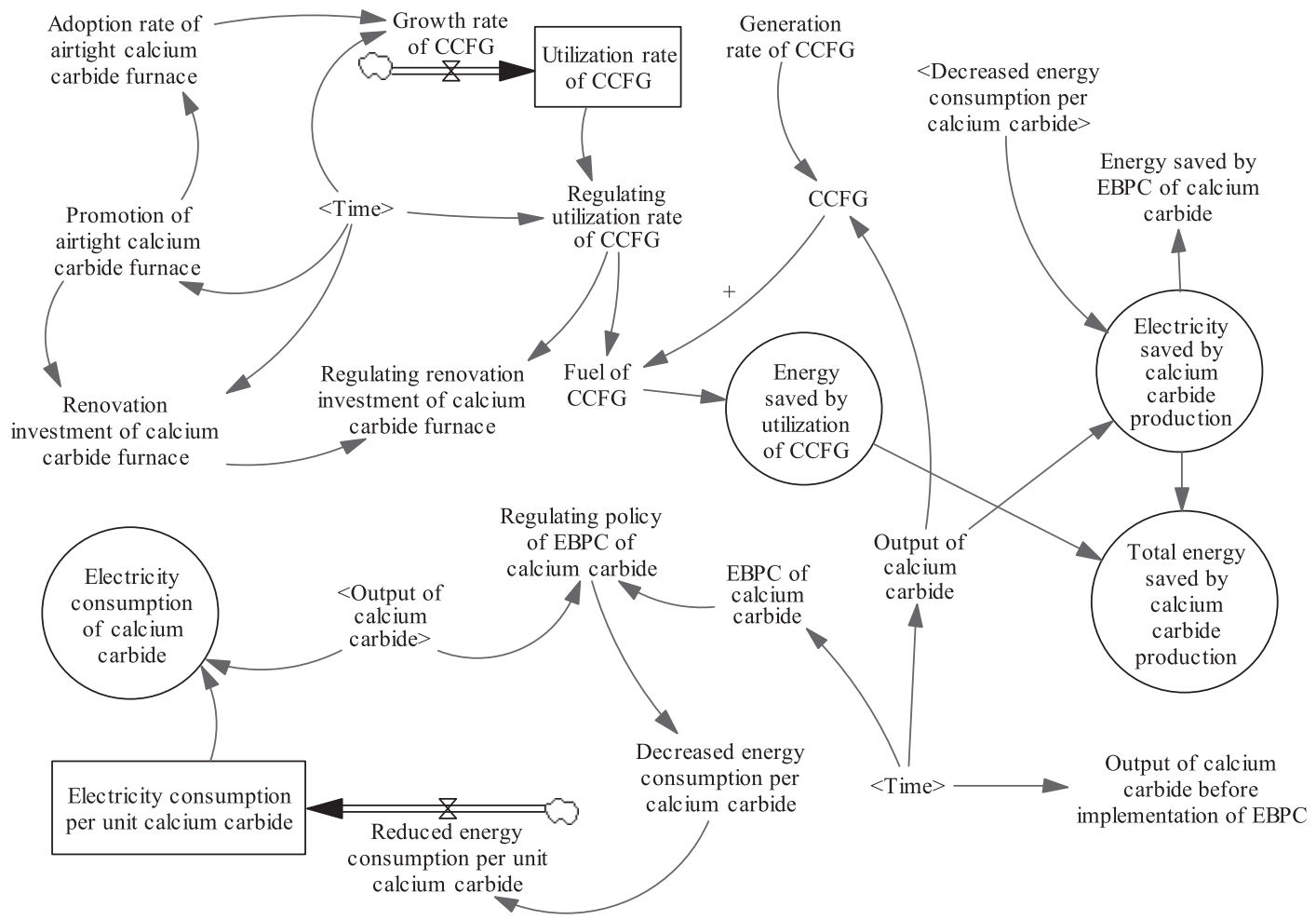

Fig. 3. Stock-flow diagram of CCFG utilization. 


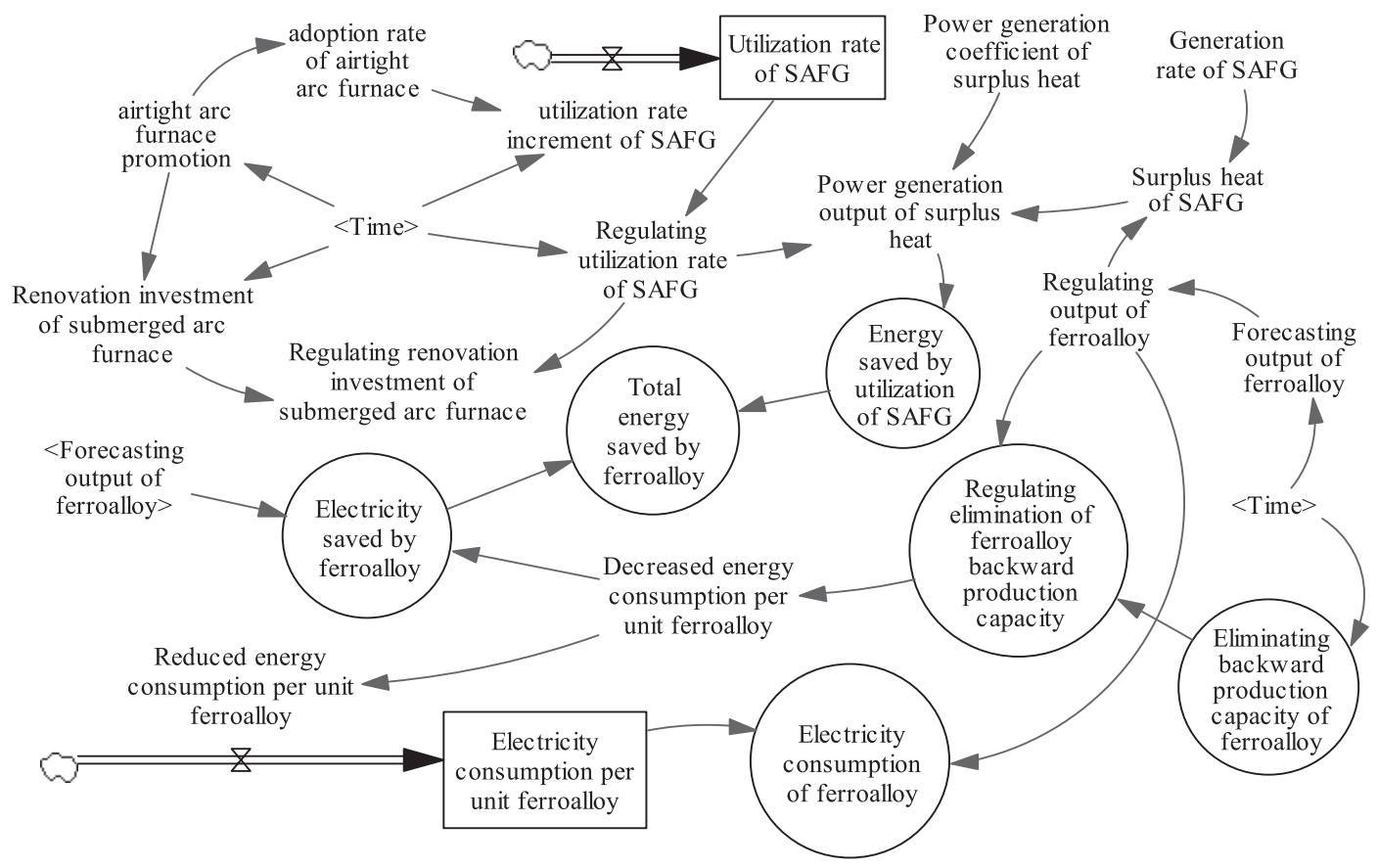

Fig. 4. Stock-flow diagram of SAFG utilization.

The submodule of BFG utilization involves 2 level variables (special steel output and invest scale), 2 rate variables (output increment and invest increment of special steel), and 18 auxiliary variables. The 2 sources of blast furnace gas are the original blast furnace iron manufacturing industry and the special steel industry, which has recently been completed and operationalized. Blast furnace gas has begun to be comprehensively used. The utilization increment of blast furnace gas comes from the gas increment, growing with the enhancement of special steel output. A stock-flow diagram of BFG utilization is shown in Fig. 2.

The submodule of CCFG utilization involves 2 level variables (electricity consumption per unit of calcium carbide output and utilization rate of calcium carbide furnace gas), 2 rate variables (energy consumption reduction per unit of calcium carbide output and utilization rate increment of calcium carbide furnace gas), and 16 auxiliary variables. This process is shown in Fig. 3. The operation of 2 policies - phasing out

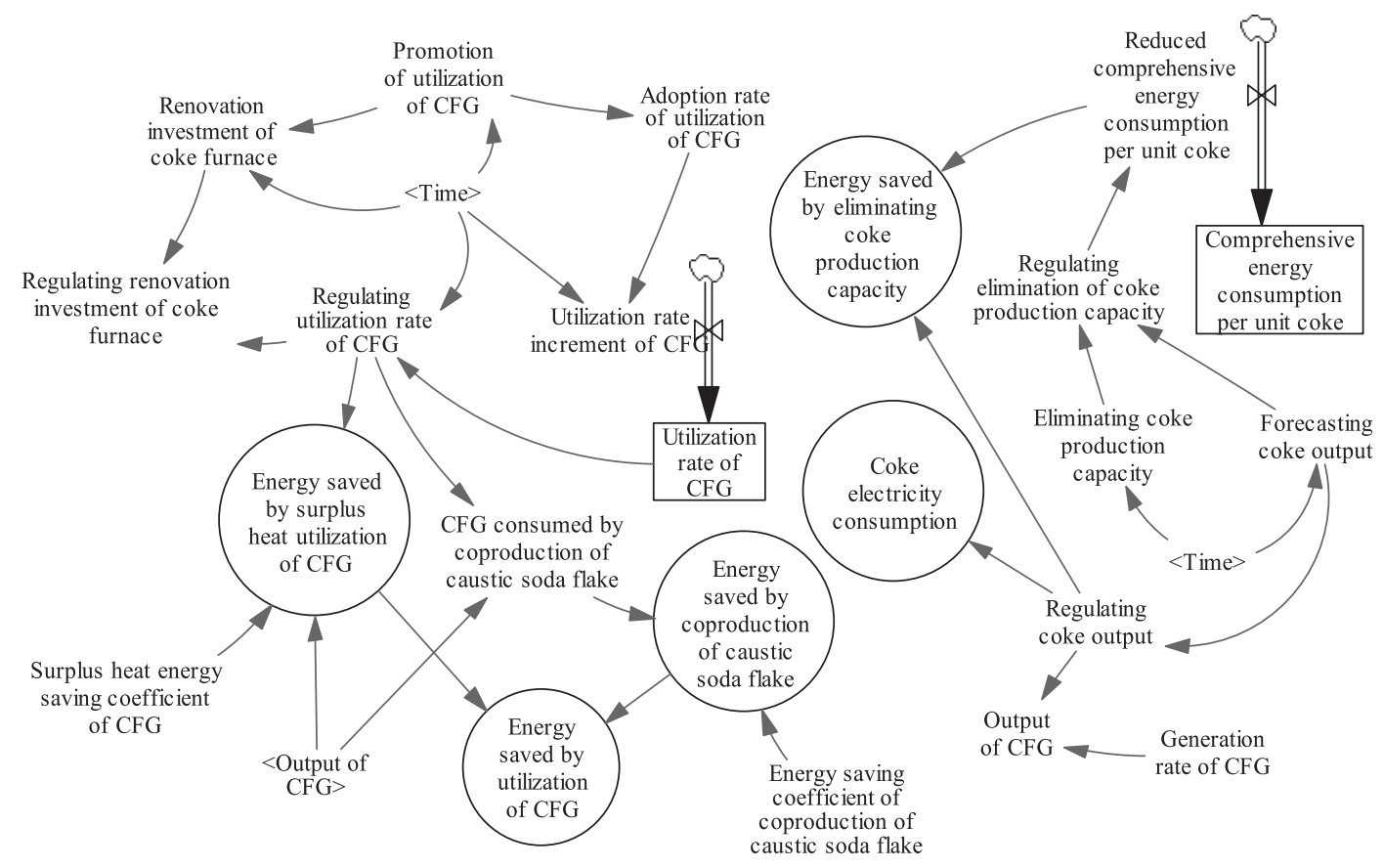

Fig. 5. Stock-flow diagram of CFG utilization. 


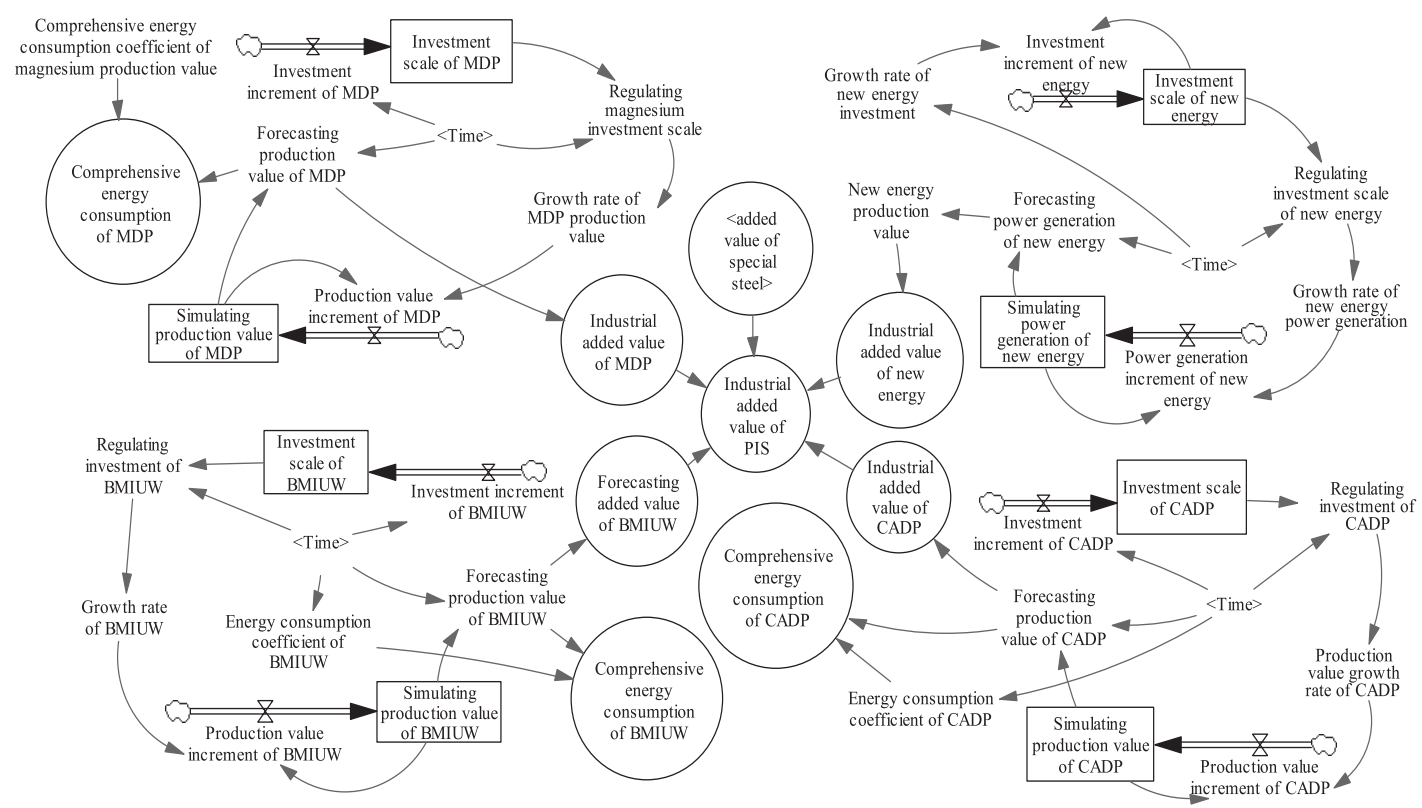

Fig. 6. Stock-flow diagram of PIS.

backward production capacity and calcium carbide furnace remodelling - are simulated. Here, energy consumption per unit of product could be reduced, and the utilization of pollutants can also generate energysaving effects.

The submodule of SAFG utilization includes 2 level variables (electricity consumption per unit of ferroalloy output and utilization rate of submerged arc furnace gas), 2 rate variables (energy consumption reduction per unit of ferroalloy output and utilization rate increment of submerged arc furnace gas), and 19 auxiliary variables. The process of submerged arc furnace gas utilization is shown in Fig. 4. The operation of 2 policies - decreased backward production capacity and submerged arc furnace renovation for a circular economy - are simulated. Here, electricity generation using surplus heat is one of the main circular economy patterns. Decreasing the production capacity

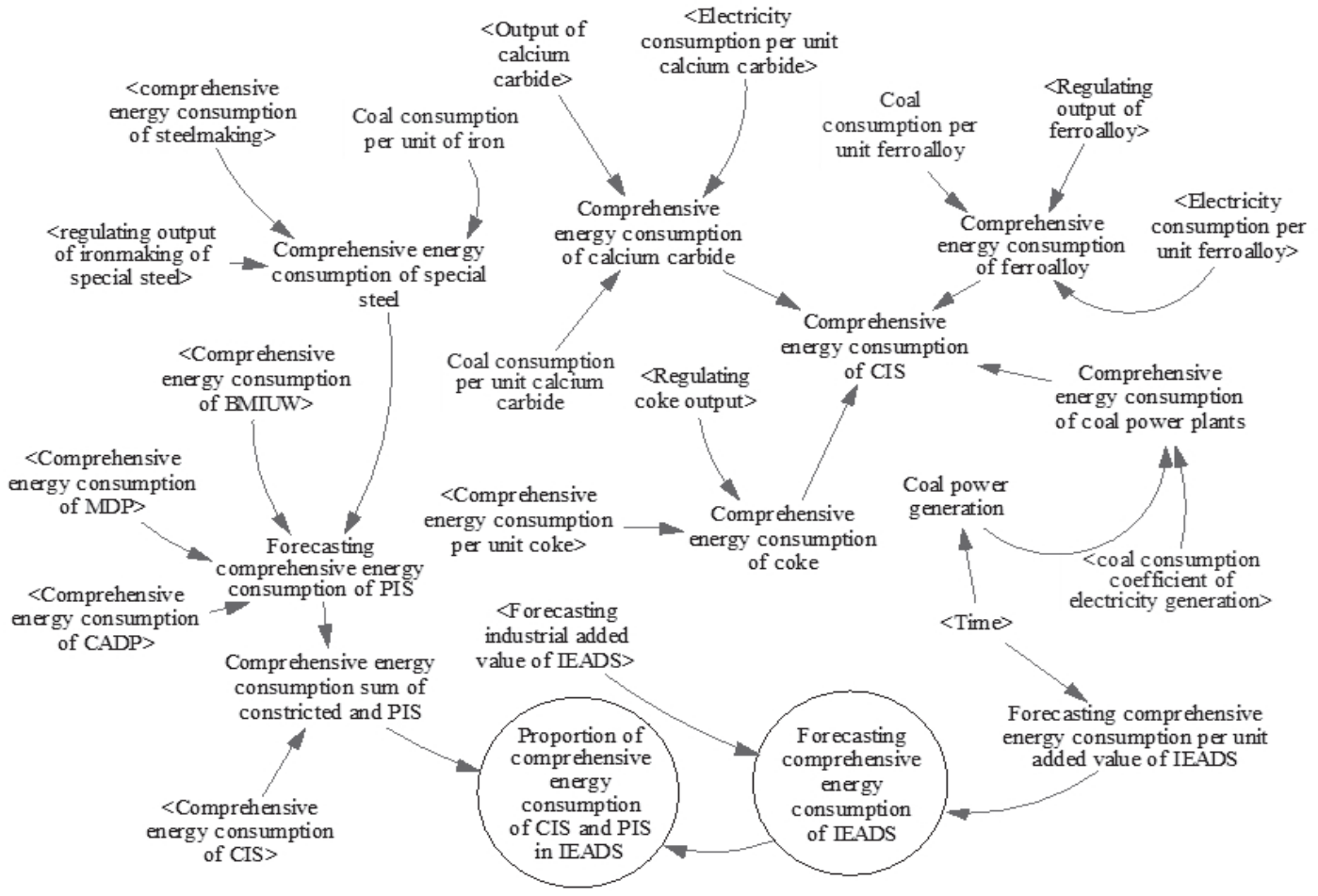

Fig. 7. Submodule of energy consumption effects. 


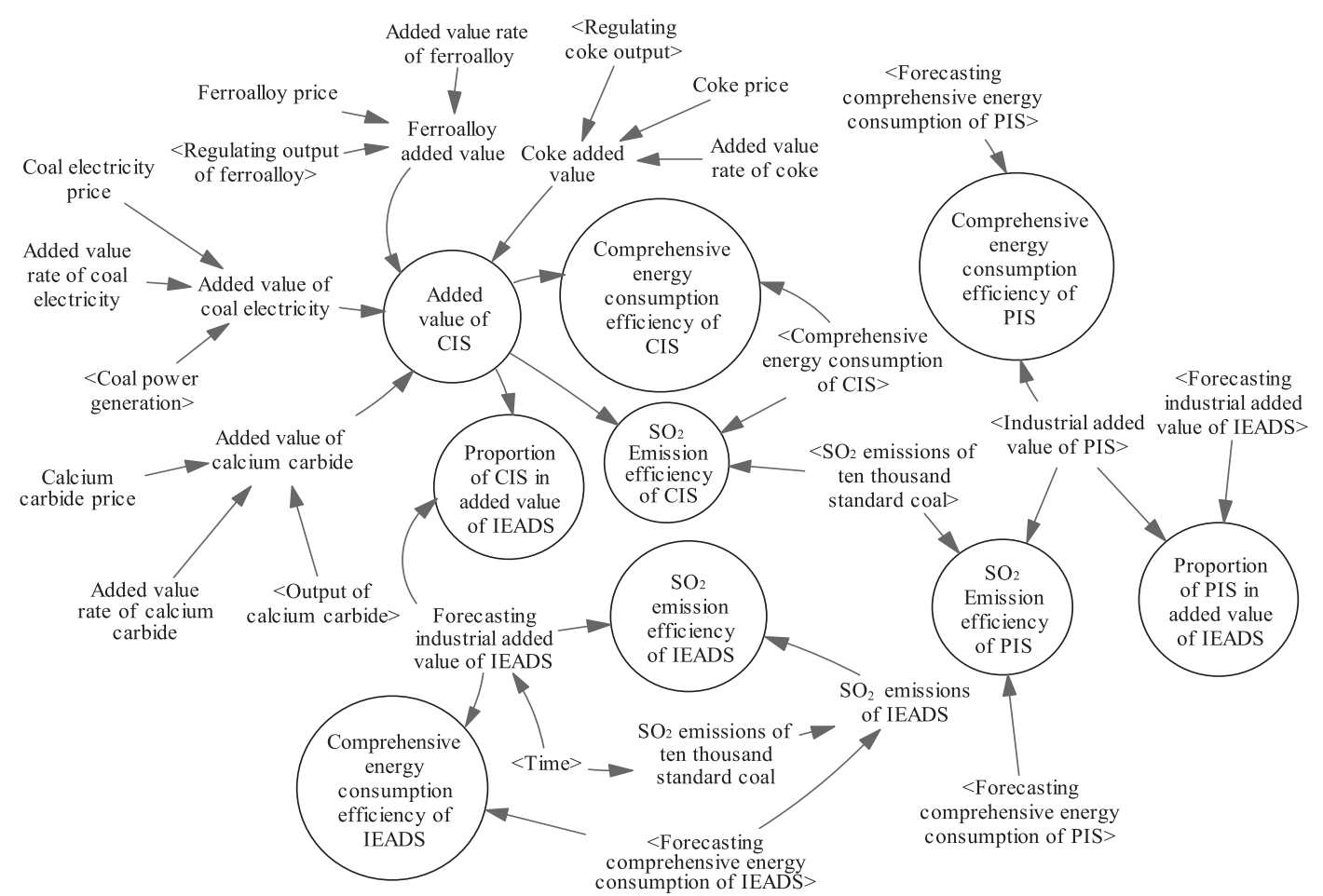

Fig. 8. Submodule of economic effects.

of the heavy energy-consuming ferroalloy industry by a certain amount can greatly reduce energy use per unit of product.

The submodule of CFG utilization involves 2 level variables (utilization rate of $\mathrm{CFG}$ and comprehensive energy consumption per unit of coke output), 2 rate variables (utilization rate increment of CFG and energy consumption reduction per unit of coke output), and 18 auxiliary variables. The treatment of CFG mainly refers to the utilization of surplus heat and coproduction of caustic soda flakes. The process of the utilization of CFG and DBPC is illustrated in Fig. 5.

It is supposed that the decreasing scale of backward production capacity would be enlarged and the manufacturing renovation intensity be improved with local regulations step by step for objectives of the eco-industry. The key goal of DBPC is to raise the effective and clean production capacity of calcium

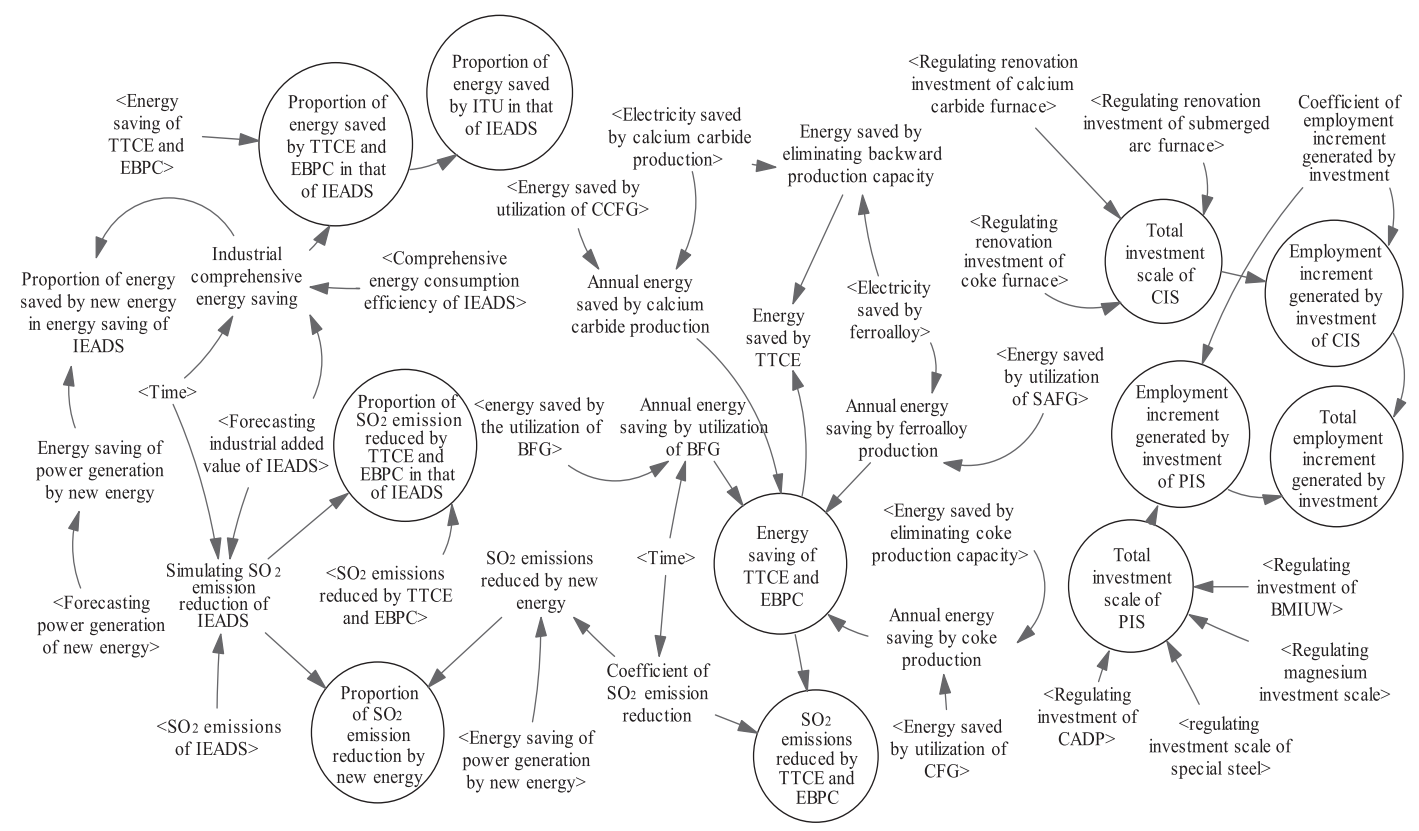

Fig. 9. Submodule of environmental-economic effects. 
carbide, coke, ferroalloy, and other industries to above $80 \%$. In addition, the local main goal of manufacturing renovation is to raise the off-gas utilization rate to above $90 \%$. The development of eco-industry is affected by its positive externality. The local public subsidy for enterprises with manufacturing renovation helps to stabilize industry ecology advancement.

\section{The Module of PIS}

According to the Planning for Huinong's Transformation toward Circular Economy and Planning for Huinong's Industrial Upgrading and Structural Adjustment, some industrial sectors, including electricity, ferroalloy, calcium carbide, and coke (FCCC), would be transformed, constricted, and diminished by industrial ecology aimed at an ecological industrial system. Meanwhile, the investment in 5 of Huinong's policy-preferential industrial sectors, including special steel, magnesium deep processing (MDP), chlor alkali deep processing (CADP), building material industry using wastes (BMIUW) and new energy, would be largely advanced, reaching about $€ 3.29$ billion, $€ 0.35$ billion, $€ 2.65$ billion, $€ 0.61$ billion, and $€ 0.47$ billion, respectively. The total investment scale would be more than $€ 7.37$ billion. Thus, it is crucial to simulate the development of these industries and their overall effects on Huinong's industrial system. Herein, MDP involves 2 level variables (investment scale of MDP and production value of MDP), 2 rate variables (investment increment of MDP and production value increment of MDP), and 6 auxiliary variables. With these variables, the study can proceed critically by simulating the development trajectory of MDP and its comprehensive energy consumption and examining its industrial added value. As a high-tech industrial sector, MDP's energy efficiency is high, and changes to its proportion in IEADS would significantly impact energy consumption and $\mathrm{SO}_{2}$ emission efficiency for the whole industrial system. In addition to MDP, the regulation and control mechanisms of the other 4 sectors are shown in Fig. 6.

\section{The Module of Regulating Effects}

The regulating objectives of the eco-industry system mainly involve economic, energy, and environmental effects. As a typical coal-based city, the exploring and employing of coal resources is the basis of regional development. Implementing eco-industry and reducing pollutants thus pertains to using coal efficiently and sustainably. For backward production transition and industrial upgrading toward an eco-industry, the adoption of a new manufacturing system that can recycle off-gas could be viewed as a certain efficient and sustainable mode. This module is designed around key objectives of eco-industry, such as saving energy and reducing emissions. Energy and environmental effects are simulated by analysing changes in energy consumption per unit of industrial added value and $\mathrm{SO}_{2}$ emission reduction efficiency with the process of industry growth. These are key indicators for assessing the system's regulating performance. In addition, the economic effects of regulating policies can be measured by analysing the increase of industrial added value. Thus, the submodule of comprehensive energy use, related to 28 auxiliary variables, simulates energy consumption with the growth trajectory of the industrial added value of IEADS and PIS (Fig. 7). The submodule of economic effects implicates 32 auxiliary variables (Fig. 8). The submodule of synthetic environmentaleconomic effects involves 50 auxiliary variables (Fig. 9).

\section{Results and Discussion}

First, the model is tested to justify its reliability and provide confidence in its application using Vensim

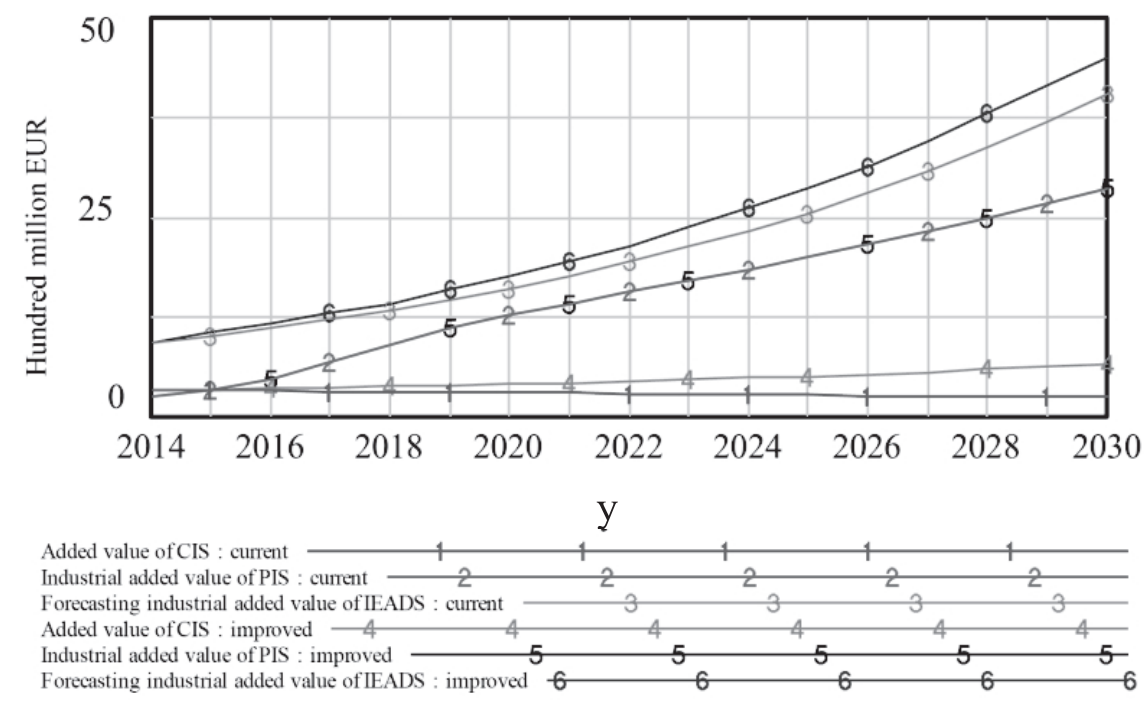

Fig. 10. Change trajectory of IEADS's industrial added value. 


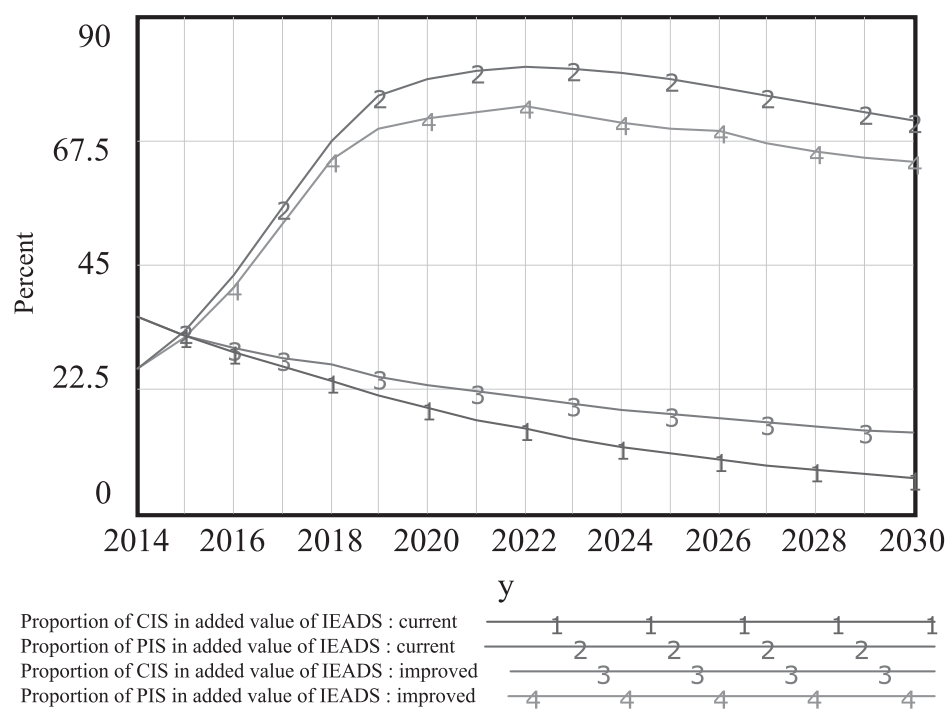

Fig. 11. Change trajectory of the proportions of CIS and PIS in IEADS added value.

software developed by Ventana Systems, which is an industrial-strength system dynamics simulation software for improving the performance of real systems (and which can be free for academic use by downloading it on vensim.com). Using its "run reality checks," reality check functions are inputted and run to validate the logical relationships among variables. All the variables are checked in the model. The results can be output automatically, and they show that all the reality checks are passed. In addition, we also examine the model's sensitivity. The tool of "automatic simulation on change" is used. By varying each parameter value from maximum to minimum, the test is executed to determine whether the simulation results of relevant variables accord with the logic. All the variables in the model are tested and pass the sensitivity test. The study then proceeds with the trend simulation of the eco-industrial system and discusses the results.

\section{Effects of the Eco-Industrial System}

Current policy governing industrial structural adjustment and transformation is aiming toward a circular economy. Huinong's industry enterprises above designated size (IEADS) have undergone obvious changes in industrial structure, growth rate, energy

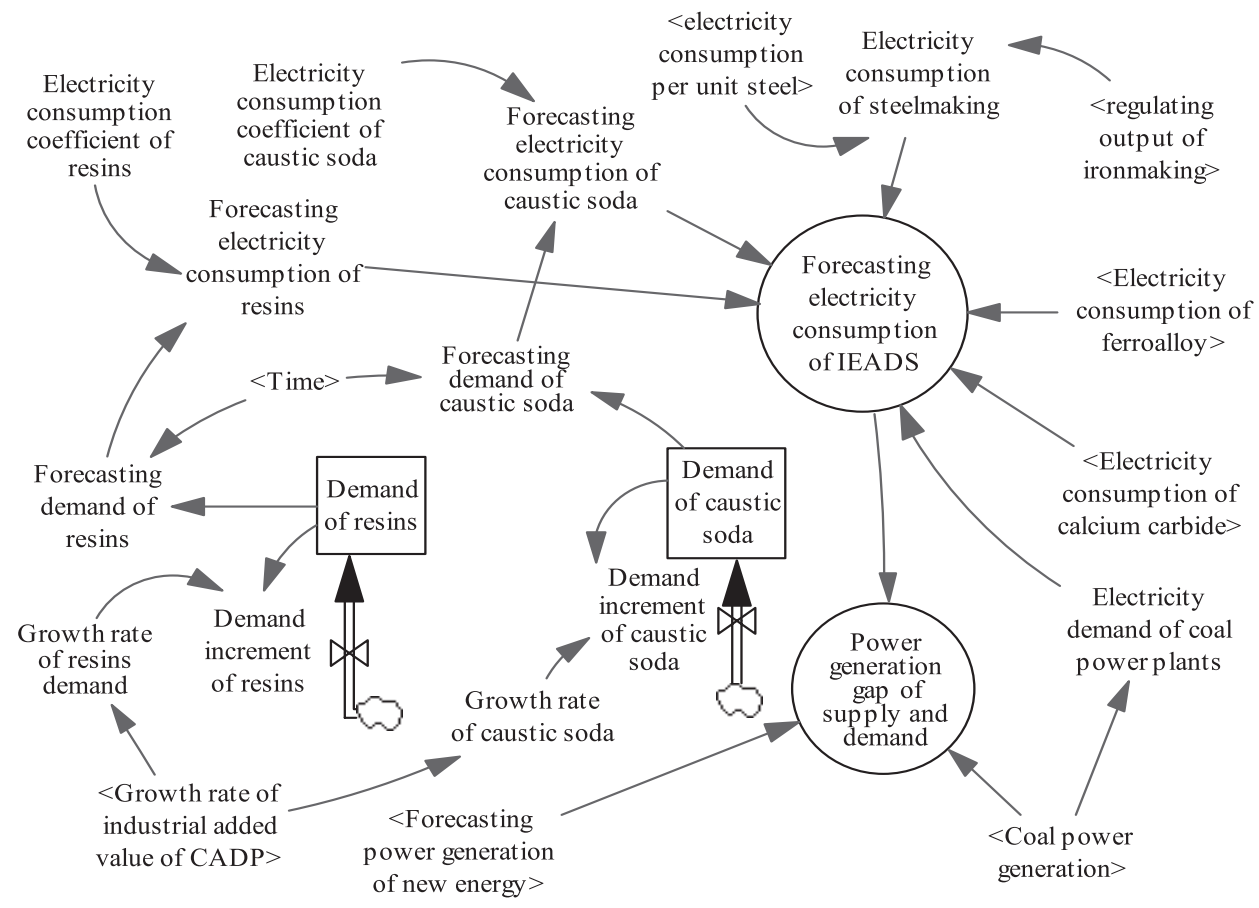

Fig. 12. Stock-flow diagram of electricity supply and demand. 


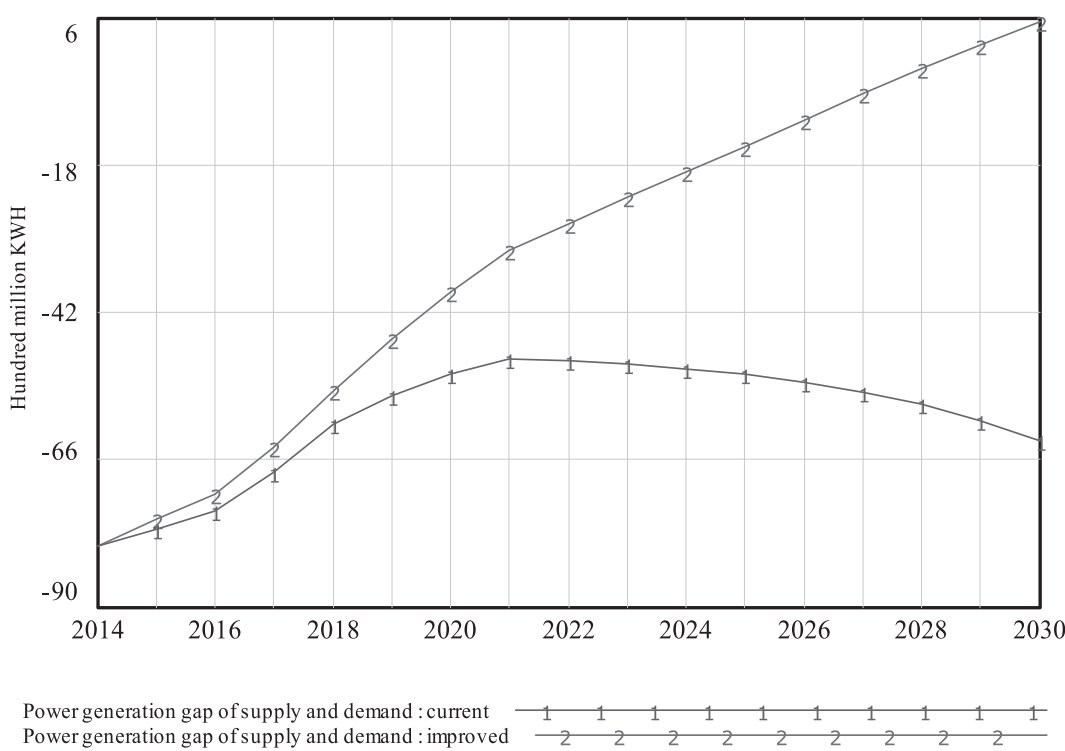

Fig. 13. Change trajectory of supply and demand gap for electricity.

consumption, and $\mathrm{SO}_{2}$ emission reduction efficiency. Then the proportion of CIS added value in IEADS would drop yearly from $62.3 \%$ in 2013 to $3.3 \%$ by 2030 , and the proportion of PIS added value in IEADS would spike and fall, reaching $56.7 \%$ by 2030 (Figs 10-11). The $\mathrm{SO}_{2}$ emission efficiency of both CIS and PIS would increase continuously. The $\mathrm{SO}_{2}$ emission efficiency rates of IEADS and PIS would exceed the national average of 2013 in 2021 and 2023, respectively. For a coalbased city, an industry structure with large-scale highenergy consumer sectors could be a key reason for low $\mathrm{SO}_{2}$ reduction efficiency in the long run. Additionally, the total energy consumption efficiency of PIS in IEADS would increase gradually as industrial structure changes. In addition, driven by PIS, the total energy consumption efficiency of IEADS will increase sharply from more than $€ 102$ to about $€ 346$ per ton of standard coal. However, Huinong's total energy consumption efficiency is still considerably lower at less than half of China's average level. This is also typical of resourcebased cities in West China and is a critical aspect of China's efforts toward global change mitigation.

\section{Supply and Demand Analysis of Main Industrial Products}

As a typical coal-based city in China, the growth of Huinong's electric power plants is based on abundant coal resources, and coal has always been one of the pillar industries in the region. To date, Huinong's

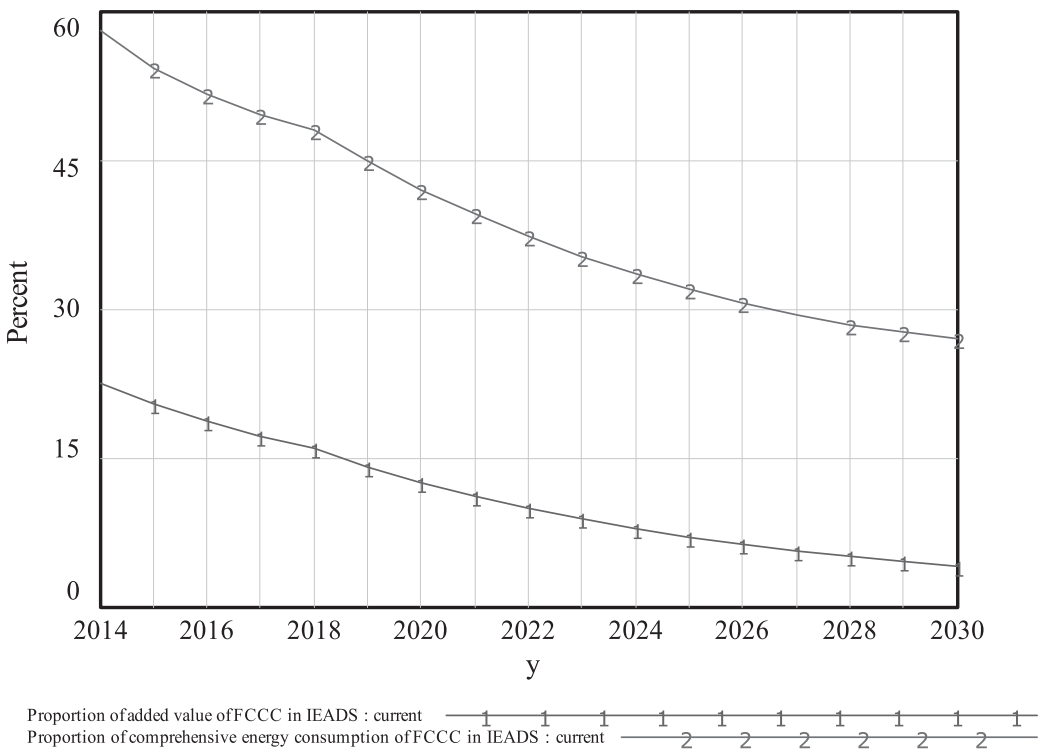

Fig. 14. Proportion of added value and energy consumption of FCCC in IEADS . 


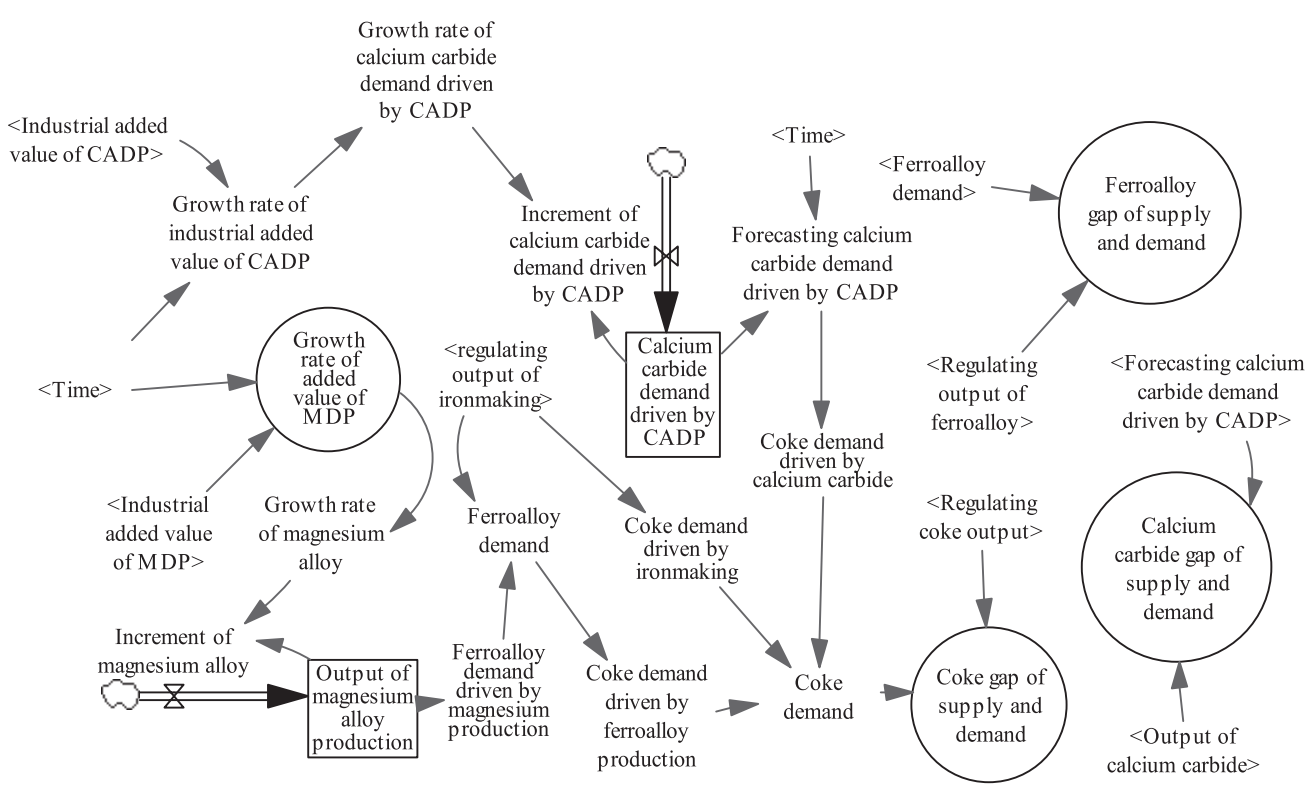

Fig. 15. Stock-flow diagram of supply and demand for ferroalloy, calcium carbide, and coke.

per capita generated electricity has consistently taken first place among Chinese cities annually. Recently, Huinong's amount of generated electricity has fluctuated. Following industrial progress, the electricity industry would still undergo an upward trend in the long run, especially with the increased power generation capacity of surplus heat or wasted gas. Huinong's supply and demand trajectory was analysed using the module of electricity supply and demand. The stockflow diagram is shown in Fig. 12. For the industrial sector of chlor alkali deep processing (CADP), the raw materials mainly include PVC resin, caustic soda, and calcium carbide, and the growth of CADP would certainly increase demand for these raw materials. For the metallurgical industry, ferroalloy is an important auxiliary material that can critically improve product quality. Given the development of the metallurgical industry, production of either normal steel or special steel would boost demand for ferroalloy, which is also necessary for the magnesium metallurgical industry. The model of electricity generation and its demand is herein constructed according to the quantitative relations of material-energy flow in the industrial chains of CEMM, LLCB, and the coal-chemical industry. As shown in Fig. 13, the decreasing electricity use of CIS and increasing energy consumption efficiency of PIS would create a future short-term gap in the supply and demand for electricity in Huinong. Ferroalloy, calcium carbide, and coke (FCCC) have long been Huinong's traditional industrial products. These industries are also high energy-consuming sectors based on local abundant and low-cost coal power and contribute largely to local

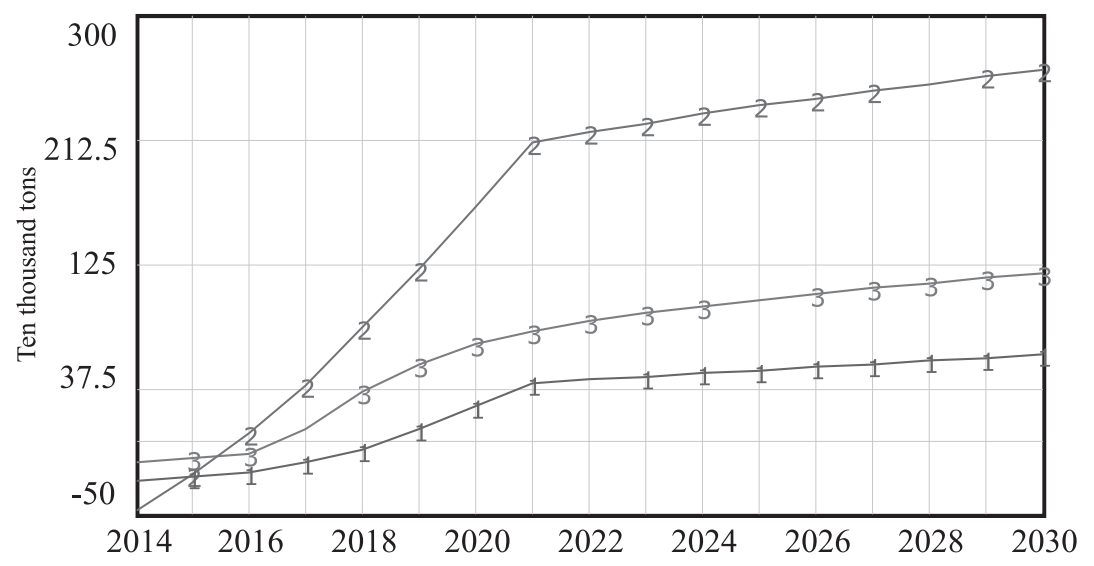

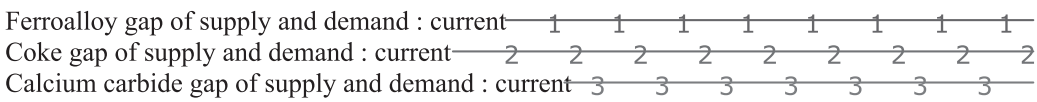

Fig. 16. Change trajectory of FCCC supply and demand. 


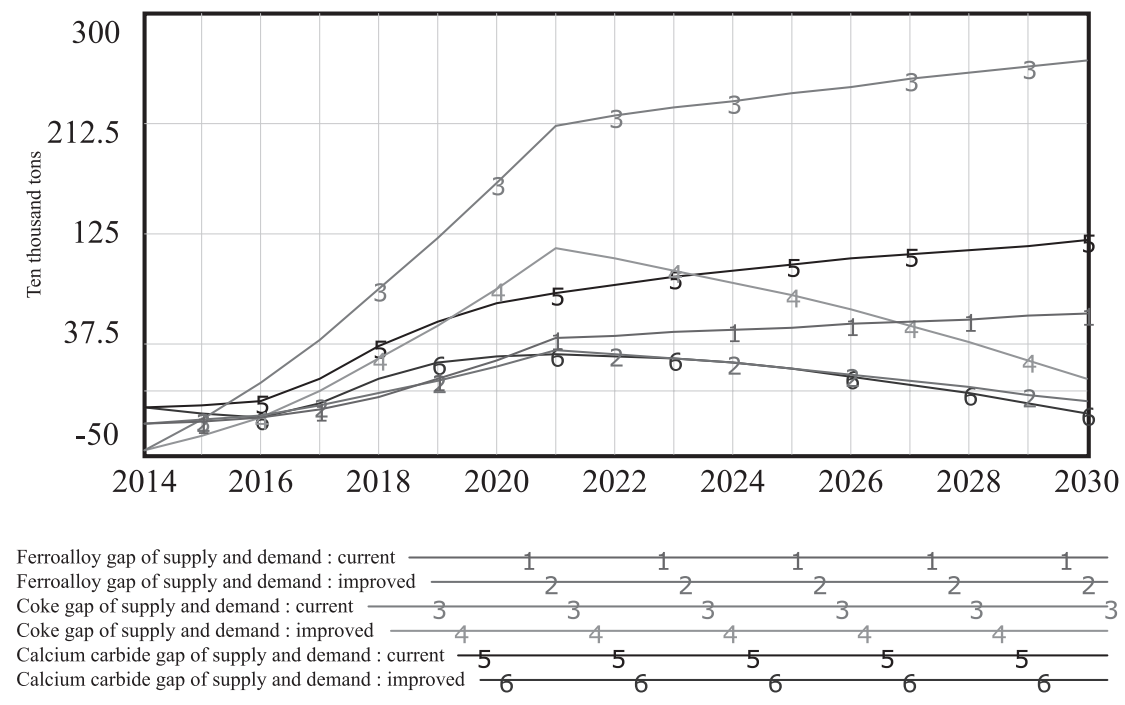

Fig. 17. Change trajectory of supply and demand gaps for ferroalloy, calcium carbide, and coke.

economic growth. However, as China's eco-industry and circular economy pilot area since 2007, energy savings and emission reduction have been among the most pressing aspects of Huinong's development. Due to large-scale industrial backward production, a capacity of over 1 million tons has been phased out, including 0.75 million tons of coke, more than 200 thousand tons of calcium carbide, and more than 50 thousand tons of ferroalloy. Thus, the FCCC industry has presented the first aporia of industrial regulation. According to plans for industrial transition and upgrading, backward production capacity would be phased out gradually by 2017, including 200 million tons of calcium carbide, 73 million tons of ferroalloy, and 446 million tons of coke. The levels of production and the corresponding energy consumption of FCCC in IEADS would descend continuously (Fig. 14). Calcium carbide is an important raw material for the chlor alkali industry, and coke is crucial for the production of iron, calcium carbide, and ferroalloy.

The stock-flow diagram in Fig. 15 analyzes the supply and demand of the ferroalloy, calcium carbide, and coke industries based on the input-output nexus of these industries. This analysis is conducted according to the quantitative relationships of material-energy flow in CEMM, LLCB, and the coal-chemical industrial chain. The production capacities of ferroalloy, calcium carbide, and coke decreased according to Huinong's local industrial policies. The output of coke in Huinong was 1.56 million tons in 2012 and dropped to just 915,000 tons in 2013. However, the demand for these industrial products did not decrease immediately. Driven by growth of PIS, such as CADP, MDP, and the iron and steel industries, demand for ferroalloy, calcium carbide, and coke would still increase to a certain point. The supply and demand gap of these products would widen in the future (Fig. 16). Some energysaving and emission-reducing policies have significantly reduced the production capacity of several high energy-consuming industries, achieving environmental benefits. However, short-term influences of high energyconsuming industries on the local economy cannot be ignored. In particular, within the new normal national economy, some industrial elimination policies should be handled discreetly, influencing the development of local environment and economy in a balanced way.

\section{The Simulation of Industrial Structure Options}

To stabilize local economic growth, industrial transformation and restructuring should be actualized gradually. Herein, the study aims to explore a hypothetical growth rate of policy-constrained industrial sectors balanced with local environmental and economic effects. The production capacity within the adjustment and elimination objectives could be expected to grow at an average rate of approximately $6.5 \%$ annually in the next 10 years, coupled with ongoing eco-industrial transformation steps. This policy simulation process is called "improved," with parameters symbolized as "improved." "Current" means a scenario that industry would grow considering that all industrial policies will remain unchanged.

\section{Effects of Industrial Structure Regulation}

As industrial policies adjust, the rate of industrial added value of IEADS would be boosted with the growth of the calcium carbide, ferroalloy, and coke industries. The proportions of added value of PIS in IEADS with "improved" have been improved substantially compared to the present circumstances (Figs 10-11). Moreover, the energy efficiency and $\mathrm{SO}_{2}$ reduction efficiency of PIS would not be obviously affected by "improved," and IEADS would still increase considerably, despite being influenced by the ferroalloy, calcium carbide, and coke industries. This hypothetical industrial growth 
rate would neither obviously harm the development of policy-preferential industries nor impact the goals of manufacturing ecology.

\section{Supply and Demand of Power Generation} and Ferroalloy, Calcium Carbide, and Coke

Electricity supply and demand would clearly be improved (Fig. 13). Similarly, the gaps of supply and demand for calcium carbide, ferroalloy, and coke would also decrease. The trends of these three kinds of products might at first rise and then fall, reaching equilibrium around 2030 (Fig. 17). This shrinking gap could generate considerable economic benefits, which would be significant for the steady progress of eco-industry in northwestern China.

\section{Conclusions}

Using the IEP-SD model, Huinong's eco-industry system was simulated and explored, focusing on a typical coal-based economy in northwestern China. Based on the model, the positive effects, potential risks, and negative actions of the eco-industry system can be identified. Furthermore, the model affords an analysis of the regulation options of industrial sectors seeking a transformation toward eco-industry while balancing environmental and economic effects. The growth of high energy-consuming industry at a certain rational rate would be reasonable for stable economic growth and industry ecology transformation, especially in the many resource-based cities of western China. Moreover, the goals of energy savings and emission reduction of eco-industry can still be locally implemented, promoting further preferential development of industrial ecology. Additionally, the balance of supply and demand between the upstream and downstream industries in such a northwestern region of China are in accord with the development philosophy of eco-industry. However, the practices of ecological industry in Huinong, and some of China's other similar resource cities, are still limited to the development concept and some government preferences. Many good experiences and modes from foreign countries could not substantially be introduced and implemented locally. There is especially a lack of consideration of such important elements as coal gasification, CCS- carbon capture, and storage to reduce the greenhouse effect. Therefore, $\mathrm{SO}_{2}$ emissions are to be reduced by using a "new energy." China could take good examples from Poland, which has dealt completely with the emissions of this gas by implementing a simple flue gas desulphurisation system in power plants, where this process can additionally give a valuable by-product: gypsum. This is the crux of what coal-based eco-industry transition can resort to in the future.

The IEP-SD model reveals the interaction and flow mechanism among eco-industry with three subsystems - industry, effect, and policy - providing a basis for pertinent eco-industry policy decisions and verifying their effectiveness. Further investigation, especially a more detailed study of comprehensive system improvement policies based on the model, is clearly needed before any unquestionable conclusion can be drawn. However, deriving the quantitative effects of the eco-industrial system helps to advance the debate over decision making. In particular, the model can give some feasible policy implications for managing and developing eco-industry in a coal-based city, providing a basis for relevant modelling studies.

\section{Acknowledgements}

This study was supported by the Shandong Social Science Fund (No. 18CSJJ14), the Research Fund of Ludong University (No. LB2017028), the a Strategic Priority Research Program of the Chinese Academy of Sciences (Environmental issues and disaster risks in key areas and important projects of the Belt and Road), the National Natural Science Foundation of China (No. 41301642), and the Foundation of Ethnic Group Culture Research Base of Nanling Corridor, Key Research Institute of Humanities and Social Sciences in Guangxi General Universities (No. 2015KF03). We also thank the administrative bureau and enterprises in Huinong for their assistance in data collection. H.Y. and F.L. contributed equally to this study.

\section{Conflict of Interest}

The authors declare no conflict of interest.

\section{References}

1. JÄNICKE M. "Green growth": From a growing ecoindustry to economic sustainability. Energ. Policy. 48, 13, 2012.

2. MURRAY A., SKENE K., HAYNES K. The circular economy: An interdisciplinary exploration of the concept and application in a global context. J. Bus. Ethics. 4, 1, 2015.

3. ASHTON W.S., CHOPRA S.S., KASHYAP R. Life and death of industrial ecosystems. Sustainability. 9 (4), 605, 2017.

4. BOULDING K.E. The economics of the coming spaceship earth. In Environmental Quality in a Growing Economy, 1st ed.; Jarrett H., Eds., Johns Hopkins University Press: Baltimore, MD, USA, 3, 1966.

5. PEARCE D.W., TURNER R.K. Economics of natural resources and the environment, 1st ed.; Harvester Wheatsheaf: London, UK, 29, 1990.

6. SU B.W., HESHMATI A., GENG Y., YU X.M. A review of the circular economy in China: moving from rhetoric to implementation. J. Clean. Prod. 42, 215, 2013.

7. SCHILLER G., MÜLLER F., ORTLEPP R. Mapping the anthropogenic stock in Germany: Metabolic evidence 
for a circular economy. Resour. Conserv. Recy. 123, 93, 2017.

8. YONG R. The circular economy in China. J. Mater. Cycles. Waste. 9 (2), 121, 2007.

9. MATHEWS J.A., TAN H. Progress toward a circular economy in China. J. Ind. Ecol. 15 (3), 435, 2011.

10. LIU Z., ADAMS M., COTE R.P., GENG Y., LI Y.Z. Comparative study on the pathways of industrial parks towards sustainable development between China and Canada. Resour. Conserv. Recy. In press. 2016.

11. FAN Y.P., BAI B.Y., QIAO Q., KANG P., ZHANG Y., GUO J. Study on eco-efficiency of industrial parks in China based on data envelopment analysis. J. Environ. Manage. 192, 107, 2017.

12. BOIX M., MONTASTRUC L., AZZARO-PANTEL C., DOMENECH S. Optimization methods applied to the design of eco-industrial parks: a literature review. J. Clean. Prod. 87, 303, 2015.

13. HOBSON K., LYNCH N. Diversifying and de-growing the circular economy: Radical social transformation in a resource-scarce world. Futures. 82, 15, 2016.

14. CHOPRA S., WU P.J. Eco-activities and operating performance in the computer and electronics industry. Eur. J. Oper. Res. 248 (3), 971, 2016.

15. BELTRÁN-ESTEVE M., PICAZO-TADEO A.J. Assessing environmental performance in the European Union: Eco-innovation versus catching-up. Energ. Policy. 104, 240, 2017.

16. MALCZYK T. Consistency of the wind power industry, including the process of sustainable planning and space management. Pol. J. Environ. Stud. 25 (2), 699, 2016.
17. SA A., THOLlANDER P., CAGNO E. Assessing the driving factors for energy management program adoption. Renew. Sust. Energ. Rev. 74, 538, 2017.

18. FORRESTER J.W. Industrial dynamics: a major breakthrough for decision makers. Harvard. Bus. Rev. 36 (4), 37, 1958.

19. KOU S., FALEBITA O.A., AKINBAMI J.K., AKARAKIRI J.B. System dynamics, uncertainty and hydrocarbon resources modelling: A systematic review. Renew. Sust. Energ. Rev. 59, 199, 2016.

20. DACKO M. System dynamics in modelling sustainable management of the environment and its resources. Pol. J. Environ. Stud. 19 (4), 699, 2010.

21. ELSAWAH S., PIERCE S.A., HAMILTON S.H., VAN DELDEN H., HAASE D., ELMAHDI A., JAKEMAN A.J. An overview of the system dynamics process for integrated modelling of socio-ecological systems: Lessons on good modelling practice from five case studies. Environ. Modell. Softw. 93, 127, 2017.

22. TAO Z.P. Scenarios of China's oil consumption per capita using a hybrid factor decomposition-system dynamics simulation. Energy. 35 (1), 168, 2010.

23. KOTIR J.H., SMITH C., BROWN G., MARSHALL N., JOHNSTONE R. A system dynamics simulation model for sustainable water resources management and agricultural development in the Volta River Basin, Ghana. Sci. Total. Environ. 573, 444, 2016. 